\title{
On-farm evaluation of maize varieties in the transitional and savannah zones of Ghana: Determinants of farmer preferences
}

\author{
Prince Maxwell Etwire $^{1 *}$, Tahirou Abdoulaye ${ }^{2}$, Kwadwo Obeng-Antwi $^{3}$, Samuel S. J. Buah ${ }^{1}$, \\ Roger A. L. Kanton', Henry Asumadu ${ }^{3}$, Mashark S. Abdulai ${ }^{1}$, Alidu Haruna ${ }^{1}$ and \\ John C. Etwire ${ }^{4}$ \\ ${ }^{1}$ CSIR-Savanna Agricultural Research Institute (CSIR-SARI), P. O. Box TL 52, Tamale, Ghana. \\ ${ }^{2}$ International Institute of Tropical Agriculture (IITA), Ibadan, Nigeria. \\ ${ }^{3}$ CSIR-Crops Research Institute (CSIR-CRI), Kumasi, Ghana. \\ ${ }^{4}$ Faculty of Mathematical Sciences, University for Development Studies, Navrongo, Ghana.
}

Accepted 4 June, 2013

\begin{abstract}
Maize is one of the most important food crops in Ghana even though its production has not reached self sufficiency levels. Drought and striga infestation are among the most important production constraints of maize in Ghana. Promising high yielding, drought and striga tolerant maize varieties are being evaluated by CSIR and IITA in participatory on-farm trials and demonstrations. These varieties however need to meet farmers' varietal preferences in order for them to adopt. This study therefore sought to assess farmers' preference for the different drought tolerant maize varieties, and determine factors that influence their choices. Kendall's coefficient of concordance was used to test the level of agreement between farmers on their preferences. The ordered logistic regression was used to estimate the determinants of farmer's preference using cross-sectional observations from 120 maize farmers in the Transitional and Savannah zones of Ghana. Results indicate that maize varieties that are early maturing (2.38) and drought tolerant (2.45) were most preferred by farmers. Area under maize cultivation, fertilizer usage and family size are the factors that were found to influence farmers' preference for improved maize varieties. These factors should therefore be considered in varietal promotion.
\end{abstract}

Key words: Drought tolerant, farmers' preferences, determinant, savannah and transition zones of Ghana, ordered logit.

\section{INTRODUCTION}

Maize (Zea mays L.) is one of the most important food cereals in the developing world. It is not only the largest staple crop in Ghana, but also the most widely cultivated crop accounting for 50 to $60 \%$ of total cereal production. Additionally, maize is the largest commodity crop in the country second only to cocoa (Millennium Development
Authority, 2010). Therefore, the importance of maize to the economy of Ghana cannot be overemphasized. The crop is a major source of food, feed and cash for many households in Ghana. Ghana is, however, not self sufficient in the production of maize because its production is faced with a number of constraints including 
low soil fertility, erratic rainfall pattern, drought, inadequate access to certified seed, poor agronomic practices, among others. It has therefore become important to develop and disseminate maize varieties that are high yielding and tolerant to the major stresses in the country in order to boost its production. The Council for Scientific and Industrial Research of Ghana (CSIR) has been collaborating with the International Institute of Tropical Agriculture (IITA) in developing and evaluating improved maize varieties suitable for various agroecological systems in Ghana. Two CSIR institutes, namely Savanna Agricultural Research Institute (CSIRSARI) and Crops Research Institute (CSIR-CRI) are responsible for developing improved maize varieties for the northern Guinea savannah, and forest and transitional zones, respectively.

Since 2008, promising high yielding, drought and striga tolerant maize varieties are being evaluated in participatory on-farm trials and demonstrations. These trials serve as important tool to showcasing the potential of new maize varieties to farmers. Additionally, the participatory on-farm testing of the varieties is also a means of facilitating rapid dissemination and adoption of these improved maize varieties by farmers. This study therefore sought to assess farmer preference for the different maize varieties that have been developed and are being evaluated. The findings from the study have important policy implications in terms of guiding breeders and agronomists in prioritizing potential varieties to concentrate on, as means of maximising scarce resources. Most studies have either used contingent valuation to identify factors influencing preference (Chern et al., 2002; Nouhoheflin et al., 2004; Parcell and Gedikoglu, 2012; Chen and Gao, 2013) or product characteristics to explain preference (Tetteh et al., 2011). This study attempts to explain preference using farmer characteristics and the determinants of preference were estimated using ordered logistic regression based on random utility theory.

\section{Study areas}

According to the Ministry of Food and Agriculture (2011), rain forest, deciduous forest, transitional zone, coastal savanna and Northern Savannah are the 5 main agroecological zones in Ghana. This classification takes into consideration climate, natural vegetation and soil types. This study was undertaken in the transitional and northern savannah zones with mean annual rainfall of 1300 and $1100 \mathrm{~mm}$, respectively. The northern savannah with a uni-modal rainfall pattern is located in northern Ghana and the transitional zone with a bi-modal rainfall pattern is located in the middle belt of the country. Differences in mean annual rainfall and distribution as well as soil types have implications for agricultural production in the two zones (Codjoe and Bilsborrow, 2011). The study district and community in the transitional zone was Techiman and Pramposo, respectively. The study districts in the savannah zone were Sissala West (Silbelle community), Wa Municipality (Kpongu community) and Garu-Tempani (Garu community).

\section{METHODOLOGY}

\section{Data}

The study used primary data collected through farmer interviews. Questionnaires were developed, tested and administered to maize farmers. Information captured by the questionnaire was mainly on socio-demographic characteristics, preferred maize varieties and reasons for preference. A multi-stage sampling technique was employed by the study. All the districts and communities were purposively sampled because they hosted an on-farm trial of the Drought Tolerant Maize for Africa (DTMA) Project Phase III. At the community level, farmers were grouped by sex and 30 farmers were sampled through simple random technique. A total of 120 farmers were interviewed in 4 communities in 4 districts. In terms of agro-ecology, 30 farmers were sampled in the transitional zone.

\section{Models}

\section{Kendell's coefficient of concordance}

Evaluation of the maize varieties was done when the crop was still on the field and almost ready for harvesting. The objective of the on-farm trial and the purpose of the variety preference ranking were explained to the sampled farmers. Farmers were asked to view all the plots before selecting the variety they liked most after which a questionnaire was administered. Farmers showed preferences for 17 varieties. These varieties were then categorized into 5 for the purpose of ranking. The highest ranked category was assigned a value of one. Categorisation of the varieties and the levels of preference are presented in Table 1. The rankings were then subjected to the Kendall's coefficient of concordance in order to measure the degree of agreement of rankings by different farmers. Following from Tetteh et al. (2011), the total rank score for each factor was computed and the factor with the least score was interpreted as the most preferred. The coefficient of concordance (equation 1) was computed using a statistical software, SPSS:

$$
W=\frac{12\left[\sum T^{2}-\frac{\left(\sum T\right)^{2}}{n}\right]}{n m^{2}\left(n^{2}-1\right)}
$$

Where $\mathrm{T}=$ sum of ranks for factors being ranked; $\mathrm{m}=$ number of farmers; and $\mathrm{n}=$ number of factors being ranked.

The Coefficient of concordance $W$ was tested for significance using the F distribution (Tetteh et al., 2011). The hypotheses tested were:

$\mathrm{H}_{0}$ : There is no agreement among farmers in ranking of maize varieties.

$\mathrm{H}_{1}$ : There is agreement among farmers in ranking of maize varieties.

\section{Ordered logit}

In modeling, the factors that influence the choice of a preferred maize variety, the study employs qualitative response regression 
models because the dependent variable, which is preference for a set of maize varieties, is not measured quantitatively. When the dependent variable is polytomous and is unordered, then the multinomial logit is appropriate and mostly used (Hassan and Nhemachena, 2008; Gbetibouo, 2009; Deressa et al., 2010). The multinomial logit is however inappropriate in instances when the dependent variable is ordered. It fails to account for the ordinal nature of the dependent variable (Greene, 2003). The ordered logit is appropriate in this situation. Empirical works that employ the ordered logit include Curtis et al. (2003) and Geda et al. (2005). The ordered logit is considered for this study because farmers were asked to rank their most preferred maize variety which enters the model as the dependent variables. The theoretical framework adopted for the qualitative response model for this study is based on the random utility model as espoused by Greene (2003).

Following from Greene (2003), the choice of a preferred maize variety may be modelled as a linear function of a vector of observable exogenous variables, $\mathrm{X}$ and an unobservable stochastic term, e:

$Y=X \beta+e$

The mean and variance of the random term is normalized to zero and one with an independent and identical logistic distribution. The model therefore has only one unknown threshold parameter and the probabilities are such that:

$$
\begin{aligned}
& \operatorname{Pr} o b(Y=0 \mid X)=1-\phi\left(X^{\prime} \beta\right) \\
& \operatorname{Pr} o b(Y=1 \mid X)=\phi\left(\mu-X^{\prime} \beta\right)-\phi\left(-X^{\prime} \beta\right) \\
& \operatorname{Pr} o b(Y=2 \mid X)=1-\phi\left(\mu-X^{\prime} \beta\right)
\end{aligned}
$$

The coefficients of the exogenous variables are not the marginal effects; the marginal effects of $X$ on the probabilities are estimated as:

$$
\frac{\partial \operatorname{Pr} o b(Y=0 \mid X)}{\partial X}=-\phi\left(X^{\prime} \beta\right) \beta
$$$$
\frac{\partial \operatorname{Pr} o b(Y=1 \mid X)}{\partial X}=\left[\phi\left(-X^{\prime} \beta\right)-\phi\left(\mu-X^{\prime} \beta\right)\right] \beta
$$

$$
\frac{\partial \operatorname{Pr} o b(Y=2 \mid X)}{\partial X}=\phi\left(\mu-X^{\prime} \beta\right) \beta
$$

For this study, $\phi$ is defined as the standard logistic distribution with mean zero and standard deviation $\delta=\pi / \sqrt{3}$. From the marginal effects equations aforementioned, it can be seen that a change in the prob $(Y=0 \mid X)$ with respect to a change in the exogenous variable $X$, has the opposite sign of beta. A change in the prob $(Y=2 \mid X)$ by a similar analogy has the same sign as beta. Hence, the marginal effects of these two probabilities are not ambiguous. A change in prob $(Y=1 \mid X)$ is however dependent on the two densities, the sign of the beta is therefore ambiguous, thus, the sign of the marginal effects is also not interpretable (Greene, 2003). This study therefore considers the effects of the exogenous variables on the endogenous variables in terms of log odds.

The parameters for the model were estimated using the maximum likelihood method. The likelihood ratio (LR) statistic was used to test the overall significance of the model (Gujarati, 2004). The model was tested for the major econometric problem associated with ordered logistic regressions. According to Green and Hensher (2009), the parallel regression assumption also known as the proportional odds assumption is a very important assumption underlying the use of the ordered logistic regression. It states that the 'independent variables' effect on the cumulative odds does not change from one cumulative odds to the next. The only thing that changes is the constant term". This implies that, the ordered logit unlike the multinomial logit model does not provide different parameter estimates for each dependent variable. Only one set of parameter estimates are provided for all the dependent variables because the cumulative odds do not change, only the constant term changes. According to Greene and Hensher (2009), Brant test can be used to determine if the proportional odds assumption has been violated or not.

STATA software was used for the estimation. A significant Brant test statistic indicates that the parallel regression assumption has been violated.

\section{Description of variables}

The dependent variables for this study are maize varieties that have been broadly categorized into 5 as presented in Table 1 . Independent variables that were considered to have an effect on farmer's choice of a preferred maize variety are sex, household headship, family size, area under maize cultivation and quantity of fertilizer used. Preference for maize varieties by men may differ from that of women. Sex is included in the model as an independent variable to capture such differences. Sex may have a negative or positive effect on preference. Several authors have posited that males have more access to, and control of resources (Hassan and Nhemachena, 2008; Deressa et al., 2010; Mandleni and Anim, 2011). Male farmers are therefore more likely to have access to different maize varieties and as a result make choices between these different maize varieties. Nhemachena and Hassan (2007) however disagree opining that, female farmers undertake most of the agricultural activities. Female farmers may therefore have an influence on the choice of maize variety that is cultivated. A household head is usually the key decision maker of the household. Household headship is therefore expected to have a positive influence on the choice of a maize variety that is cultivated by the household. As a result of cash constraints, it is not uncommon for farmers to apply less than the recommended fertilizer rates. The average quantity of fertilizer applied, which can be used as a proxy for wealth, is expected to have a positive effect on the choice of a maize variety by a farmer. Increase in family size means increased consumption which consequently has a negative effect on household income (Shehu and Mshelia, 2007; Maganga, 2012). Family size may therefore have a limiting effect on the number of options of maize varieties available; hence, family size may have a negative influence on the decision to choose between different maize varieties.

According to Simonyan et al. (2011) and Ezeh et al. (2012), an increase in family size implies an increase in family labour. The additional labour can be channelled into production of different maize varieties; hence, family size could also have a positive influence on the decision to choose between different maize varieties. Farm size is expected to have a positive effect on the decision to choose between different maize varieties. 
Table 1. Categorisation and levels of preference for maize varieties.

\begin{tabular}{lcc}
\hline Variety & Most preferred variety selected by sample (\%) & Category \\
\hline 2004 TZEE-W Pop STR C4 & 9.2 & \\
TZEEI 29 × TZEEI 21 & 7.5 & \\
TZEE-W Pop STR QPM C0 & 5.0 & TZE (34.2\%) \\
TZE Comp 3 DT C2F2 & 5.0 & \\
TZEE-Y Pop STR C5 × TZEEI 82 & 3.3 & \\
99 TZEE Y STR C1 & 1.7 & \\
99 TZ WW Y STR & 1.7 & DT (17.4\%) \\
TZEEI 49 x TZEEI 29 & 0.8 & \\
& & \\
DT SR W CO F2 & 11.4 & SYN (11.7\%) \\
DT STR SYN & 4.7 & \\
DT SR W C2 & 1.3 & \\
& & \\
2000 Syn EE-W STR & 7.5 & Others (26.7\%) \\
2008 Syn EE-W DT STR & 4.2 & \\
PAN 53 & & \\
L0904 27 & 10.0 & Local (10.0\%) \\
IWD C3 SYN F2 & 8.3 & 4.2 \\
M0926 8 & 4.2 & \\
Local check (various) & 10.0 & \\
\hline
\end{tabular}

Deressa et al. (2009) opines that farmers with large farm sizes are also wealthier farmers and therefore have the resources to invest into different farming options.

\section{RESULTS AND DISCUSSION}

\section{Socio-demographic characteristics of respondents}

The use of improved maize varieties by farmers in northern Ghana and to a large extent Ghana as a whole is pervasive (Wiredu et al., 2010). All the farmers interviewed were found to have been using improved maize varieties for at least 10 years. It was observed that most varieties perceived by farmers to be traditional were in fact developed or introduced by research even though in some cases they were developed a long time ago and have been recycled by farmers over the years. Even though majority (80\%) of the sample were still cultivating an improved maize variety, only $25 \%$ reported knowing the difference between hybrids and openly pollinated varieties (OPVs). Farmers therefore tend to give all maize varieties the same treatment, selecting seeds from previous harvest of both OPVs and hybrids thereby culminating in yield loss as a result of loss in hybrid vigour. The average age of the sampled farmers was 41 years. The experience of the farmers in either cultivate improved maize varieties in particular or engaging in maize production in general, could have had an influencing factor on farmer's selection of their most preferred maize variety. The summary statistics of the independent variables that were considered to have an effect on farmers' preferences for maize varieties are presented in Table 2. On the average, each farmer interviewed had a family size of 10 people.

According to the Ghana Statistical Service (2008), the mean household size in rural savannah of Ghana is 5 people. Family labour is a significant contributor to the labour requirements of most cropping systems in Ghana; hence, farmers with larger family sizes are less likely to be labour constrained during the peak cropping season. About $58 \%$ of the farmers interviewed were heads of their household. The average maize area cultivated was estimated to be 1 ha. Agriculture in Ghana is on a smallholder basis with majority (90\%) of farmers cultivating less than 2 ha (MoFA, 2011). A large family and farm size is normally considered as an indication of prosperity and may affect one's social status in most farming communities in Ghana. The average inorganic fertilizer usage was estimated to be $283 \mathrm{~kg} / \mathrm{ha}$. With declining soil fertility, most farmers will record low or no yield without fertilizer application. About $48 \%$ of the respondents were females.

\section{Farmer's ranking of maize varieties}

The results of farmers' rankings of their preferred maize 
Table 2. Summary statistics.

\begin{tabular}{lcccc}
\hline Variable & Minimum & Maximum & Mean & Standard deviation \\
\hline Family size & 1 & 28 & 9.975 & 5.173 \\
Maize area $(\mathrm{Ha})$ & 0.10 & 6.00 & 1.054 & 0.992 \\
Fertilizer quantity $(\mathrm{kg})$ & 0 & 800 & 283 & 200.2 \\
Relative frequency & & & & \\
Sex & Female (47.5\%) & & & \\
& Male (52.5\%) & & \\
Household head & Yes (58.3\%) & & & \\
\hline
\end{tabular}

Table 3. Farmers ranking of preferred maize varieties.

\begin{tabular}{lccc}
\hline \multirow{2}{*}{ Category } & & Mean rank & \\
\cline { 2 - 4 } & Transition & Savannah & Overall \\
\hline TZE & 2.65 & 2.29 & 2.38 \\
DT & 1.40 & 2.80 & 2.45 \\
SYN & 3.37 & 2.96 & 3.06 \\
Other & 2.92 & 3.42 & 3.30 \\
Local & 4.67 & 3.53 & 3.81 \\
& & & \\
Test statistics & & & \\
N & 30 & 90 & 120 \\
Kendall's W & 0.56 & 0.10 & 0.14 \\
Chi-Square & 67.33 & 36.17 & 69.15 \\
df & 4 & 4 & 4 \\
Asymp. Sig. & $0.00^{\star \star \star}$ & $0.00^{\star \star \star}$ & $0.00^{\star \star \star}$ \\
\hline
\end{tabular}

a. Kendall's coefficient of concordance. ${ }^{* *}$ Significant at $1 \%$ level.

varieties are presented in Table 3. Analysis of the results indicated that earliness is the most preferred trait required by farmers for their maize varieties. Those varieties with TZE (meaning early maize) in their pedigree received the highest ranking (2.38) in terms of farmer preference. Early and extra early maize varieties enable farmers to have an early harvest which is critical considering the fact that the harvesting period is usually the lean season. These varieties are also usually harvested before the end of the regular season thereby enabling the crop to escape some biotic and abiotic stresses that may affect regular maize production. The second most preferred varieties were the DT category (that is, drought tolerant varieties) with the various local checks been ranked as the least preferred. Drought tolerant varieties are increasingly becoming important with increasing unreliability and unpredictability of the weather pattern. The Kendell's coefficient of concordance indicates that about $14 \%$ of the sample agrees with each other on the rankings. Analysis of the rankings by ecology reveals that the various local checks are the least preferred varieties. The local checks were perceived to be drought and striga susceptible and therefore low yielding.

Farmers however revealed different preferences for their most preferred variety. Whereas, farmers in the savannah zone preferred early and extra early varieties, farmers in the transitional zone preferred drought tolerant varieties. The level of agreement among farmers in terms of the rankings, were 56 and $10 \%$ for the transitional and savannah zones respectively.

\section{Determinants of preference}

The overall model is statistically significant suggesting that the model with predictors is to be chosen over a model without repressors in explaining determinants of 
Table 4. Determinants of preference.

\begin{tabular}{|c|c|c|c|}
\hline Variable & Odds ratio & Robust standard error & $P>Z$ \\
\hline Sex & 0.839 & 0.434 & 0.734 \\
\hline Household head & 1.054 & 0.514 & 0.914 \\
\hline Family size & $1.057^{\star}$ & 0.349 & 0.091 \\
\hline Maize area & $0.638^{\star *}$ & 0.114 & 0.012 \\
\hline Fertilizer quantity & $1.002^{\star *}$ & 0.001 & 0.025 \\
\hline Cut 1 & -0.218 & 0.406 & \\
\hline Cut 2 & 0.552 & 0.409 & \\
\hline Cut 3 & 0.991 & 0.412 & \\
\hline Cut 4 & 1.596 & 0.422 & \\
\hline Number of obs & 120 & & \\
\hline Wald $\mathrm{Chi}^{2}(5)$ & 11.94 & & \\
\hline Prob $>\mathrm{Chi}^{2}$ & 0.036 & & \\
\hline Pseudo $\mathrm{R}^{2}$ & 0.024 & & \\
\hline Log pseudo likelihood & -177.098 & & \\
\hline
\end{tabular}

${ }^{*},{ }^{* *}$ represents statistical significance at 10 and $5 \%$, respectively.

Table 5. Brant test of parallel regression assumption.

\begin{tabular}{lccc}
\hline Variable & $\mathbf{C h i}^{\mathbf{2}}$ & Prob $>\mathbf{C h i}^{\mathbf{2}}$ & df \\
\hline All & 14.34 & 0.500 & 15 \\
Sex & 2.59 & 0.460 & 3 \\
Household head & 5.09 & 0.165 & 3 \\
Family size & 3.80 & 0.284 & 3 \\
Maize area & 5.15 & 0.161 & 3 \\
Fertilizer quantity & 3.53 & 0.316 & 3 \\
\hline
\end{tabular}

A significant test statistic provides evidence that the parallel regression assumption has been violated.

farmer preference. Parameter estimates of the model showed that area under maize cultivation, fertilizer usage and family size are the factors that influence farmer's preference for improved maize varieties as shown in Table 4. Results of the Brant test presented in Table 5 also indicated that the parallel regression assumption has not been violated justifying the use of the ordered logit regression technique. Area under maize was found to have a positive and significant influence on farmer's choice of a maize variety. The log odds in favour of selecting a preferred maize variety increases by 0.638 units if a farmer puts an additional hectare of land under maize cultivation. Farmers usually try new varieties on a small piece of land before wide scale adoption takes place after they have been found to be preferable. It is not uncommon for farmers to cultivate more than one variety on a parcel of land if it is large. Farmers with larger farm sizes are therefore more likely to show preference for different maize varieties unlike those with only a small piece of land that may not be able to effectively support several varieties of maize. Farm size is mostly considered as an indication of manliness or wealth in most farming communities in Ghana.

Farmers who are therefore able to manage an additional hectare of maize are more likely to be able to buy newly improved varieties as compared to resource poor farmers. The choice of an improved maize variety could therefore be explained by the amount of land kept under maize cultivation. It is not unusual for farmers with large maize farms to have several plots at different locations. Different plots may be suitable for different varieties thus farmers with large farm sizes are more likely to show preference for different maize varieties as compared to farmers with small farm size who may be constrained to utilize only one maize variety. The findings of this study is consistent with Kankwamba et al. (2012) who also reported a positive and significant relationship between farm size and farmers choice to participate in improved seed technology transfer. Application of inorganic fertilizer was found to have a positive and significant relationship on farmer's preference for a maize variety. Application of an additional unit of inorganic 
fertilizer increased the odds ratio in favour of choosing any preferred maize variety by 1.00 units. In Ghana, inorganic fertilizers and certified seeds are sold by agroinput dealers; hence, farmers are likely to purchase certified seeds and inorganic fertilizers from the same agro-input shop.

Farmers who are able to afford additional inorganic fertilizers are more likely to be able to purchase certified seeds. There is therefore a high likelihood of such farmers showing preference for different maize varieties. Inorganic fertilizers have shown to be more effective on improved seed as compared to traditional varieties. Farmers who apply additional inorganic fertilizers are more likely to be cultivating improved varieties and are therefore more likely to show preference for different maize varieties. Most agricultural related interventions in Ghana with input support usually provide farmers with both inorganic fertilizers and certified seed. The farmers upon imbibing the importance of using certified seeds and inorganic fertilizers are more likely to use both inputs together; hence, farmers with access to inorganic fertilizers are more likely to be exposed to several maize varieties and therefore show preference for different maize varieties. Parameter estimates of the model shows a positive relationship between preference for maize varieties and family size. Increasing the family size by an additional unit increases the odds ratio in favour of choosing a preferred maize variety by 1.06 units. Farmers with large families usually have members with diverse taste. Whereas, some members may prefer maize varieties that have good roasting properties when green, others may prefer maize varieties that have good cooking or milling properties. A farmer with a large family size is therefore more likely to show preference for different maize varieties. The extended family system is still pervasive in most farming communities in Ghana. It is common for grown up or married children to live and work with their parents in the same household. Such large families may cultivate different varieties of maize; hence, the likelihood of a farmer experiencing and showing preference for different maize varieties increases with family size.

Access to labour is not usually a problem for farmers with large families. Such farmers are therefore more likely to either try new varieties or cultivate multiple varieties since labour may not be a limiting factor. Family size therefore seems to be important in determining the choice of any preferred maize variety. Kankwamba et al. (2012) also reported a positive and significant relationship between household size and farmer' decision to use improved seed of groundnut and pigeon pea.

\section{Conclusion}

Factors that were found to influence farmer preference for improved maize varieties are area under maize cultivation, fertilizer usage and family size. Maize varieties that are early maturing and drought tolerant are most preferred by farmers in the savannah and transition zones of Ghana, respectively. Breeding for other important maize traits such as striga tolerance, high yielding, resistance to lodging among others, should also take into consideration earliness and drought tolerance. For maximum adoption and impact, access to land, fertilizer and labour are important factors that need to be taken into consideration for effective promotion and dissemination of improved maize varieties.

\section{ACKNOWLEDGEMENTS}

The authors are grateful to the Drought Tolerant Maize for Africa Project, Phase III, for funding this study. The authors also acknowledge Zakaria Achulo, Haruna Ali, Solomon Antuona and Emmanuel Ansoba for administering the questionnaire.

\section{ABBREVIATIONS}

CRI, Crops Research Institute; CSIR, Council for Scientific and Industrial Research; DTMA, Drought Tolerant Maize for Africa; GSS, Ghana Statistical Service; IITA, International Institute of Tropical Agriculture; MiDA, Millennium Development Authority; MoFA, Ministry of Food and Agriculture; SARI, Savanna Agricultural Research Institute.

\section{REFERENCES}

Chen X, Gao Z (2013). Chinese Consumer Knowledge, Perception and Willingness to Pay (WTP) for Orange Juice Products: Any Opportunities for the U.S. Juice Producers? Selected Paper prepared for presentation at the Southern Agricultural Economics Association (SAEA) Annual Meeting, Orlando, Florida, 3-5 February. Available at http://ageconsearch.umn.edu/bitstream/143104/2/SAEAXuqi_Gao.pdf.

Chern WS, Rickertsen K, Tsuboi N, Fu T (2002). Consumer Acceptance and Willingness to Pay for Genetically Modified Vegetable Oil and Salmon: A Multiple-Country Assessment. Ag Bio Forum. 5(3):05-112. Available at http://agbioforum.org/v5n3/v5n3a05-chern.htm.

Codjoe NAS, Bilsborrow RE (2011). Population and Agriculture in the Dry and Derived Savannah zones of Ghana. Popul Environ. Available at http://www.ug.edu.gh/rips/pub/Codjoe_SN_April_2011PopEnvt.pdf 23-1-13.

Curtis RK, McCluskey JJ, Wahl TI (2003). Westernization in China: A Case Study in Processed Potatoes. American Agricultural Economics Association Annual Meeting, Montreal, Canada, July 27-30.

Deressa TT, Hassan RM, Ringler C (2009). Assessing Household Vulnerability to Climate Change: The Case of Farmers in the Nile Basin of Ethiopia. IFPRI Discussion Paper No. 00935. International Food Policy Research Institute, Washington, D.C.

Deressa TT, Ringler C, Hassan RM (2010). Factors Affecting the Choices of Coping Strategies for Climate Extremes: The Case of Farmers in the Nile Basin of Ethiopia. IFPRI Discussion Paper No. 01032. International Food Policy Research Institute, Washington, D.C.

Ezeh Cl, Anyiro CO, Chukwu JA (2012). Technical Efficiency in Poultry Broiler Production in Umuahia Capital Territory of Abia State, Nigeria. Greener J. Agric. Sci. 2(1):001-007. 
Gbetibouo AG (2009). Understanding Farmers' Perceptions and Adaptations to Climate Change and Variability: The Case of the Limpopo Basin, South Africa. IFPRI Discussion Paper No. 00849. International Food Policy Research Institute, Washington, D.C.

Geda A, Niek de J, Kimenyi MS, Germano M (2005). Determinants ofPoverty in Kenya: A Household Level Analysis. Economics Working Papers. Paper 200544. Available at http://digitalcommons.uconn.edu/econ_wpapers/200544.

Ghana Statistical Service, GSS (2008). Ghana Living Standards Survey Report of the Fifth Round (GLSS 5). Accra, Ghana. P. 131.

Greene HW (2003). Econometric Analysis. $5^{\text {th }}$ Edition, Pearson Education, Inc., Upper Saddle River, New Jersey, USA. P. 1026.

Greene HW, Hensher DA (2009). Modeling Ordered Choices. Available at

http://pages.stern.nyu.edu/ wgreene/DiscreteChoice/Readings/Order edChoiceSurvey.pdf.

Gujarati ND (2004). Basic Econometric. $4^{\text {th }}$ Edition, The McGraw-Hill Companies. P. 1002.

Hassan R, Nhemachena C (2008). Determinants of African farmers' Strategies for Adapting to Climate Change: Multinomial Choice Analysis. Afr. J. Agric. Resour. Econ. 2(1):83-104.

Kankwamba H, Mangisoni J, Simtowe F, Mausch K, Siambi M (2012). Improved Legume Seed Demand Systems in Central Malawi: What do Farmers' Seed Expenditures say about their Preferences? International Association of Agricultural Economists Triennial Conference. Foz do Iguaçu, Brazil, 18-24 August. Available at http://ageconsearch.umn.edu/bitstream/131684/2/H_kankwamba_IA AEx.pdf.

Maganga AM (2012). Technical Efficiency and its Determinants in Irish Potato Production: Evidence from Dedza District, Central Malawi. J. Agric. Envion. Sci. 12(2):192-197.

Mandleni B, Anim FDK (2011). Climate Change Awareness and Decision on Adaptation Measures by Livestock Farmers. 85rd Annual Conference of the Agricultural Economics Society. Warwick University, 18 - 20 April.

Millennium Development Authority, MiDA (2012). Available at http://www.mcc.gov/documents/investmentopps/bom-ghana-englishgrain.pdf.

Ministry of Food and Agriculture, MoFA (2011). Agriculture in Ghana: Facts and Figures (2010). Accra, Ghana. P. 53.

Nhemachena C, Hassan R (2007). Micro-Level Analysis of Farmers' Adaptation to Climate Change in Southern Africa. IFPRI Discussion Paper No. 00714. International Food Policy Research Institute, Washington, D.C.
Nouhoheflin T, Coulibaly O, Cherry AJ, Al-Hassan R, Adegbola PY (2004). Consumers' Perceptions and Willingness to Pay for organic vegetable in Benin and Ghana, African Association of Agricultural Economists, Shaping the Future of African Agriculture for Development: The Role of Social Scientists. Proceedings of the Inaugural Symposium. 6 to 8 December, Grand Regency Hotel, Nairobi, Kenya. Available http://ageconsearch.umn.edu/bitstream/9525/1/cp04no01.pdf.

Parcell JL, Gedikoglu H (2012). Consumer Preference Variation between Domestic and Imported Food. Selected paper prepared for presentation at the Agricultural and Applied Economics Association's 2012 AAEA Annual Meeting, Seattle, Washington. August 12-14. Available http://ageconsearch.umn.edu/bitstream/124183/2/AAEA\%202012\%2 OArtisan\%20Cheese\%20Final.pdf.

Shehu JF, Mshelia SI (2007). Productivity and Technical Efficiency of Small-scale Rice Farmers in Adamawa State, Nigeria. J. Agric. Soc. Sci. 3(4):117-120.

Simonyan JB, Umoren BD, Okoye BC (2011). Gender Differentials in Technical Efficiency among Maize Farmers in Essien Udim Local Government Area, Nigeria. Int. J. Econs. Manage. Sci. 1(2):17-23.

Tetteh AB, Adjetey NAS, Abiriwe SA (2011). Consumer Preferences for Rice Quality Characteristics and the Effects on Price in the Tamale Metropolis, Northern Region, Ghana. Int. J. Agric. Sci. 1(2):67-74.

Wiredu NA, Gyasi KO, Abdoulaye T, Sanogo D, Langyintuo A (2010). Characterization of Maize Producing Households in the Northern Region of Ghana. Country Report - Ghana: CSRI/SARI - IITA, Ibadan, Nigeria. P. 24. 